\title{
Los supuestos del pensamiento político y jurídico de Jürgen Habermas
}

\author{
Mauro Benente*
}

\section{RESUMEN}

El modo en el que Habermas reconstruye la legitimidad del derecho y del poder político moderno incluye una importante renovación del lenguaje utilizado para pensar la política. Si la teoría política nos tenía acostumbrados a un registro conceptual referido al conflicto, la administración de violencia, la utilización de la fuerza, el antagonismo de clases sociales, el par amigol enemigo, la necesidad de construir estrategias para avanzar hacia mejores condiciones de vida, en la obra del autor alemán estas nociones son sustituidas por la cooperación, intercambio de buenas razones, primacía del mejor argumento y acuerdo entre ciudadanos libres e iguales. En este trabajo me interesa remarcar aquellos aspectos que la propuesta teórica de Habermas no explica porque los da por supuestos.

Igualdad - deliberación - consenso

\section{The assumptions of political and legal thought of Jürgen Habermas}

\begin{abstract}
The way that Habermas reconstructs the legitimacy of the law and the modern political power includes a major renovation of the language used to thinks the politics. If political theory used to use a conceptual record based on the conflict, the management of violence, the use of force, the antagonism of classes, the couple friendlenemy, the need to build strategies to advance towards better living conditions, in the work of German author those notions are replaced by cooperation, exchange of good reasons, the primacy of the better argument, the agreement between free and equal citizens. In this work I am interested to note those aspects that Habermas's theoretical proposal does not explain because they are assumed.
\end{abstract}

Equality - deliberation - consensus

* Doctor en Derecho, Universidad de Buenos Aires. Becario del Consejo Nacional de Investigaciones Científicas y Técnicas. Profesor Adjunto en la Facultad de Derecho de la Universidad de Buenos Aires. Correo electrónico: maurobenente@yahoo.com

Artículo recibido el 16 de marzo de 2015 y aceptado para su publicación el 21 de enero de 2016. 


\section{INTRODUCCIÓN}

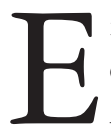

n 1951 Jorge Luis Borges escribió unas breves líneas tituladas "Kafka y sus precursores" y en el último párrafo sentenció que "cada autor crea sus precursores" 1 . Algo de ello parece estar presente en un trabajo de Jon Elster, quien adjudica a la obra de Jürgen Habermas el actual interés por la democracia deliberativa, pero encuentra precursores en la democracia ateniense del siglo V a.C., la Independencia de los Estados Unidos, la Revolución Francesa, y en autores como John Stuart Mill ${ }^{2}$. Apelando al registro del diálogo y el consenso para delinear los contornos del derecho y la política, Habermas ha creado a sus precursores. Pero también algo de ello parece estar presente en el propio método reconstructivo con el que trabaja, porque él crea los supuestos que ya estaban presentes en el derecho y el poder político moderno. Así como Kafka creaba a los autores que ya habían escrito, Habermas crea a sus precursores y también crea los supuestos -el diálogo y el consenso entre los ciudadanos- que, al igual que sus precursores, ya existían.

La capacidad de abordar diferentes temáticas, tradiciones teóricas y disciplinas, hace de la producción de Habermas una obra asombrosa. Similar asombro genera su reflexión acerca de la política y el derecho, pero en este caso llama la atención el desplazamiento semántico que presentan sus trabajos: si la teoría política nos tenía acostumbrados a un registro conceptual referido al conflicto, la utilización de la fuerza, el antagonismo de sectores sociales, la necesidad de construir estrategias para avanzar hacia mejores condiciones de vida, en su obra estas nociones son sustituidas por la cooperación, el intercambio de buenas razones entre ciudadanos libres e iguales, la primacía del mejor argumento, y el consenso racional.

En este trabajo me interesa presentar el modo en que Habermas reconstruye, con esta nueva gramática, la legitimidad del derecho y el poder político moderno. En la primera parte doy cuenta de trabajos y conferencias que datan de la segunda parte del decenio de 1980, donde ya se advierte una reconstrucción de la legitimidad del derecho en términos procedimentales. La segunda parte estará dedicada a los desarrollos de Facticidad y validez y a presentar la derivación del sistema de los derechos y la legitimación del poder político a partir del poder comunicativo. Además de exponer su propuesta teórica, me interesará remarcar algunos de sus desarrollos más potentes: que los individuos, libres e iguales, estarían interesados en regular sus comportamientos por medio del derecho; que en los procesos comunicativos que fundan la legitimidad del derecho no hay relaciones de poder; que el resultado del proceso de deliberación es el acuerdo, etc. En particular destacaré que Habermas no se esfuerza por mostrar cómo lograremos la igualdad de los ciudadanos, cómo es posible separar los procesos comunicativos de las relaciones de poder, ni cómo el resultado del diálogo es el acuerdo, sino que asume

${ }^{1}$ Borges, J. L., "Kafka y sus precursores”, en Obras completas. 1923-1972, Emecé, Buenos Aires, 1974, pp. 711 .

${ }^{2}$ Elster, J., “Introduction”, en Elster, J. (ed.), Deliberative Democracy, Cambridge University Press, Cambridge 1998. 
y supone la igualdad, la comunicación libre de relaciones de poder, y el acuerdo entre todos y todas. En este orden de ideas enunciaré la oposición que realiza Chantal Mouffe entre democracia deliberativa y democracia agonística, aunque también diré que mis críticas hacia el autor alemán no son idénticas a las desarrolladas por la autora belga.

En la presentación de la obra de Habermas quizás abuse de las citas textuales, pero esto obedece a que deseo exponer sus desarrollos con la mayor fidelidad, para así dar sustento a lo que entiendo que en lugar de explicar supone. Esto puede resultar tedioso pero creo que peor sería exponer críticas a su obra presentándola de modo deficiente -algo que entiendo que Habermas suele hacer- ${ }^{3}$.

\section{UNA NUEVA CLAVE DE LEGITIMIDAD DEL DERECHO Y EL PODER POLÍTICO}

\section{La legitimidad del derecho}

Hacia la segunda mitad del decenio de 1980 las preocupaciones teóricas de Habermas transitaron el sendero de la legitimidad del derecho y del poder político moderno. En un contexto posmetafísico, en el que ya no es posible sustentar la legitimidad del derecho en Dios ni en valores universales, resulta urgente encontrar otros criterios de legitimidad. Es así que en estos primeros trabajos traza dos líneas que, con algunas modificaciones, fueron mantenidas a lo largo del tiempo: a) la clave para dotar de legitimidad al derecho debe buscarse en los procedimientos que lo instituyen; b) no se pone en duda la legitimidad del derecho, sino que usando un análisis reconstructivo se buscan sus fundamentos implícitos ${ }^{4}$.

En la edición de 1986 de las prestigiosas Tanner Lectures presentó dos lecciones, la primera de ellas titulada “¿Cómo es posible la legitimidad a partir de la legalidad?”. Allí partió del famoso diagnóstico de Max Weber, según el cual la legitimidad del derecho moderno radica en sus cualidades formales ${ }^{5}$. Tras distanciarse de algunos de los postulados weberianos, Habermas sostuvo que solo una racionalidad procedimental dotada de contenido moral puede inyectar legitimidad al derecho moderno: "[u]na dominación ejercida en las formas del derecho positivo obligando siempre a dar razones y fundamentaciones, debe su legitimidad al contenido moral implícito de las cualidades

3 A modo de ejemplo, relativo a las graves deficiencias en la presentación que Habermas hace de Foucault, ver Benente, M. "El Foucault de Habermas bajo sospecha”, en Revista nómadas. Revista crítica de ciencias sociales y jurídicas, $\mathrm{N}^{\circ} 35,2012$.

${ }^{4} \mathrm{Si}$ bien no me interesa detenerme en este punto, Habermas asume que el derecho moderno es legítimo y coactivo, por lo que en su proyecto teórico está asumida, y de ningún modo cuestionada, la legitimidad de la coacción. Acerca de la coacción como uno de los elementos constitutivos del derecho moderno, ver Habermas, J., "La lucha por el reconocimiento en el Estado democrático de derecho", en La inclusión del otro. Estudios de teoría política, Paidós, Barcelona, 1999, p. 202.

${ }^{5}$ Cfr. Weber, M., Economía y sociedad I, Fondo de Cultura Económica, México DF, 1944, pp. 225-235. 
formales del derecho" 6 . Ante la imposibilidad de sustentar la legitimidad del derecho en valores metafísicos, la estrategia es reconstruirla a partir de la legalidad misma, pero instituida bajo ciertas reglas procedimentales. Es por ello que la legalidad solo puede engendrar legitimidad en la medida en "que se institucionalicen procedimientos jurídicos de fundamentación que sean permeables a los discursos morales" 7 .

Por su lado, en “¿Cómo es posible la legitimidad por vía de la legalidad?”, un artículo publicado en 1987 en Justicia Crítica con el mismo título que aquella conferencia, pero con diferencias en su contenido, también apostaba por dotar de legitimidad al derecho en términos de una racionalidad procedimental, pero en el caso de los procedimientos jurídicos solo podía esperarse un cumplimiento aproximado de las exigencias de una racionalidad procedimental perfecta ${ }^{8}$. De todos modos insistía en que era necesario que los procedimientos de fundamentación permitan el ingreso de los argumentos morales?

En estos primeros trabajos la legitimidad del derecho depende de la institucionalización de un tipo de procedimiento que sea permeable a los discursos morales. Pero además de este compromiso con el procedimiento, y el entrelazamiento entre el derecho y la moral, Habermas confía en el consenso entre los participantes del proceso. Es así que en la segunda lección de las Tanner Lectures, titulada "Sobre la idea de Estado de Derecho”, sostenía que la legitimidad de los procedimientos legislativos supone que los discursos políticos "queden sometidos a las restricciones impuestas por el principio de que los resultados de esos discursos puedan ser susceptibles de asentimiento general, es decir, a las restricciones impuestas por el punto de vista moral, que hemos de respetar cuando se trata de fundamentar normas" ${ }^{10}$. La indicación de someter los objetivos políticos a las restricciones impuestas por el punto de vista moral, implica que pueden existir tensiones entre los objetivos políticos y la estructuración discursiva que debemos constituir al momento de fundamentar normas. Asumir la existencia de esta tensión no es irrelevante, porque Habermas no expone cuál es el toque de magia necesario para dejar a un lado aquellos objetivos políticos que no puedan adecuarse a esta estructura de fundamentación. Asimismo, y este es otro elemento central, Habermas desliza que la consecuencia natural de la deliberación es el acuerdo de todos. Tal como reitera en trabajos posteriores, en estos primeros textos insiste en la legitimidad brindada por el procedimiento, pero supone que este concluye en un consenso. Dicho de otro modo, la legitimidad del derecho descansa no solamente en el procedimiento deliberativo, sino también en el acuerdo de todos. Lo que aquí no explica, y entiendo que tampoco sucede en trabajos posteriores, es cómo estos dos elementos que fundan la legitimidad del derecho logran conectarse. Sin proceso deliberativo no hay derecho legítimo. Sin consenso y asentimiento de todos y cada uno tampoco. Aquello que no sabemos, incluso

\footnotetext{
${ }^{6}$ Habermas, J., "Derecho y moral", en Facticidad y validez, Trotta, Madrid, 2005, p. 555.

${ }^{7}$ Habermas, J., "Derecho y moral”, en Facticidad y validez, Trotta, Madrid, 2005, pp. 556-557.

${ }^{8}$ Habermas, J., “¿Cómo es posible la legitimidad por vía de la legalidad?”, en Doxa, No 5, 1988,

${ }^{9}$ Habermas, J., “¿Cómo es posible la legitimidad por vía de la legalidad?”, en Doxa, No 5, 1988, p. 39.

${ }^{10}$ Habermas, J., "Derecho y moral”, en Facticidad y validez, Trotta, Madrid, 2005, p. 585.
} pp. 37-40. 
suponiendo que están dadas las condiciones ideales de habla y que los interlocutorios se arrodillan ante el mejor argumento, es cómo de la deliberación deviene el consenso.

\section{La legitimidad del poder político}

En una conferencia pronunciada en 1988, titulada "La soberanía popular como procedimiento", la temática analizada no fue la legitimidad del derecho sino la posibilidad de legitimar al poder político moderno en términos procedimentales ${ }^{11}$. Tal como lo presenta en la conferencia, el poder político es legítimo en tanto y en cuanto sea generado comunicativamente. Así como el poder administrativo responde a una racionalidad instrumental, el poder político responde a una racionalidad normativa que en contextos posmetafísicos debe ser edificada en términos procedimentales, comunicativos. Ahora bien, estas razones normativas no pueden ser construidas al interior del sistema político, no pueden ser establecidas por las propias instituciones políticas, sino que ellas tienen que sustentarse en prácticas que se generan fuera de ellas: en espacios informales de la sociedad civil. Esos procedimientos, que tienen por finalidad establecer una voluntad racional que dote de legitimidad al poder político, "solo pueden conducir a una formación racional de la voluntad, en la medida en que la formación organizada de la opinión [...] permanezca permeable a los valores, temas y argumentos, libremente flotantes" ${ }^{2}$. Sin embargo, así como para dotar de legitimidad a los procedimientos legislativos es requisito moralizar los objetivos políticos, la interacción que otorga legitimidad al poder político exige dejar de lado las relaciones de poder: los resultados racionales se desarrollan "en la interacción entre la formación institucionalmente organizada de la voluntad política y las corrientes de comunicación espontáneas en un espacio público no distorsionado por relaciones de poder" 13 .

Diálogo racional y consenso es la gramática con la que Habermas comienza a pensar la legitimidad del derecho y del poder político en la segunda parte de la década de 1980. Este registro se mantuvo en su obra central sobre la temática: Facticidad y validez.

\section{El Sistema de LOS DEREChOS Y EL ESTAdo DE DERECHO}

En 1992 Habermas publica Facticidad y Validez, una obra central de la teoría política y jurídica contemporánea que tiene por objetivo avanzar hacia una "reconstrucción racional de la autocomprensión de estos órdenes jurídicos modernos"14. Por un lado despliega una

${ }^{11}$ En Facticidad y validez establecerá una íntima conexión entre la legitimidad del sistema de los derechos y la del poder político, pero aquí todavía ello no se percibe con tanta notoriedad.

${ }^{12}$ Habermas, J., "La soberanía popular como procedimiento", en Facticidad y validez, Trotta, Madrid, 2005, p. 610.

${ }^{13}$ Habermas, J., "La soberanía popular como procedimiento”, en Facticidad y validez, Trotta, Madrid, 2005, p. 611. Las itálicas me pertenecen.

${ }^{14}$ Habermas, J., Facticidad y validez, Trotta, Madrid, 2005, p. 147. 
poderosa reconstrucción del sistema de los derechos, y una de sus apuestas es plantear una relación conceptual necesaria entre la autonomía privada y la autonomía pública. Pero además, siempre de acuerdo con su labor reconstructiva, postula que el sistema de los derechos exige una institucionalización en el marco de un Estado de derecho, que se caracteriza por situar la legitimidad del poder político en el poder comunicativo construido en instancias informales de la sociedad civil.

\section{La conexión interna entre soberanía popular y derechos del hombre}

Una de las apuestas teóricas más ambiciosas de Habermas es dar cuenta de la conexión interna que existe entre soberanía popular y derechos del hombre, entre autonomía privada y autonomía pública. Los derechos humanos y el principio de la soberanía popular son los dos únicos criterios que permiten que el derecho moderno sea tenido como legítimo pero tanto para las tradiciones liberales cuanto para las republicanas no se presuponen ni se complementan sino que se encuentran en competencia ${ }^{15}$. De modo bien distinto, Habermas postula que la utilización de un concepto discursivo del derecho permite dar cuenta de la mutua implicación, de la conexión interna, de la relación conceptual necesaria que existe entre la soberanía popular y los derechos humanos, o entre la autonomía pública y la autonomía privada.

Habermas emplea el principio del discurso para reconstruir el sistema de los derechos y con ello soldar la fractura existente entre los derechos del hombre y el principio de la soberanía popular. Reconstruye los derechos que los ciudadanos se otorgarían mutuamente en caso de querer regular su convivencia por el derecho positivo ${ }^{16}$, y encuentra que la autolegislación de los ciudadanos "exige que aquellos que están sometidos al derecho como destinatarios suyos, puedan entenderse a la vez como autores del derecho"17. Ya en los primeros pasos de su labor reconstructiva supone un asentimiento de todos y cada uno de los ciudadanos.

Esta concepción de autolegislación no puede reducirse a una mera autolegislación moral, sino que tiende a institucionalizar el principio del discurso bajo la forma de un principio democrático que dota de legitimidad al derecho. Además, esta concepción permite alumbrar la mutua implicación entre autonomía privada y autonomía pública: “[1]a cooriginalidad de autonomía privada y autonomía pública muéstrase solo cuando desciframos y desgranamos en términos de teoría del discurso la figura de pensamiento que representa la «autolegislación», figura conforme a la cual los destinatarios son a la vez autores de sus derechos" ${ }^{18}$. Si adoptamos el ideal de la autolegislación encontraremos la

${ }^{15}$ Habermas, J., "Derechos humanos y soberanía popular: Las concepciones liberal y republicanas", en Derechos y libertades. Revista del Instituto Bartolomé de las Casas, N³, 1994, p. 221.

${ }^{16}$ Habermas, J., Facticidad y validez, Trotta, Madrid, 2005, p. 147.

${ }^{17}$ Habermas, J., Facticidad y validez, Trotta, Madrid, 2005, p. 186.

${ }^{18}$ Habermas, J., Facticidad y validez, Trotta, Madrid, 2005, p. 169. En una entrevista de 1994 agregaba que "[1]a autonomía privada y la autonomía ciudadana se presuponen recíprocamente. Y esta cooriginalidad de soberanía popular y derechos del hombre se explica porque la práctica de la autolegislación ciudadana 
cooriginalidad y la equiprimodialidad entre autonomía privada y autonomía pública, que implica que "[n]i el ámbito de la autonomía política de los ciudadanos viene restringido por los derechos naturales o morales [...] ni tampoco la autonomía privada del individuo queda simplemente instrumentalizada para los fines de una legislación soberana" ${ }^{19}$. El establecimiento de un código jurídico bajo el principio del discurso implica reconocer que los derechos de libertad "son condiciones necesarias que no hacen más que posibilitar el ejercicio de la autonomía política; y como condiciones posibilitantes, no pueden restringir la soberanía del legislador, aun cuando no estén a disposición de este, es decir, aun cuando no pueda disponer de ellos a voluntad" 20 .

Por su lado, en "El vínculo interno entre Estado de derecho y democracia", un artículo publicado dos años después que Facticidad y validez, reitera que la filosofía del derecho y la teoría política han fracasado en la tarea de resolver la tensión que existe entre la soberanía popular y el imperio de la ley garantizado por los derechos humanos, pero la teoría discursiva de la democracia permite saldar esta deuda. Para dar cuenta de la conexión interna entre autonomía privada y autonomía pública postula que: a) la autonomía jurídica de los ciudadanos exige de los destinatarios puedan concebirse como autores del derecho; b) solamente pueden ser autores si cuentan con derechos políticos; c) para ejercer los derechos políticos se les debe garantizar el respeto a su autonomía privada $^{21}$. La apuesta teórica más importante es dar cuenta de esta cooriginalidad y equiprimordialidad entre la autonomía pública y la autonomía privada, pero como destaca Perry Anderson esta (re)construcción es completamente ahistórica, ya que en ningún Estado moderno se han consagrado de modo simultáneo. Es por ello que con algo de ironía postula que la "idea de «cooriginalidad» no pertenece ni a las ciencias políticas ni a la jurisprudencia, sino a una familia antropológica: el mito de los orígenes” 22.

tiene que institucionalizarse en forma de derechos de participación política; pero esto presupone el status de personas jurídicas como portadores de derechos subjetivos; y tal status no puede existir sin los clásicos derechos de libertad; no puede haber derecho positivo sin tales derechos: y el derecho positivo es precisamente el único lenguaje en que los ciudadanos pueden asegurarse y garantizarse mutuamente la participación en la práctica de la autolegislación, es decir, la participación en la producción de leyes que solo así puede entenderse como leyes que los ciudadanos se imponen a sí mismos". Habermas, J. "El vínculo interno entre Estado de Derecho y Democracia”, en La inclusión del otro. Estudios de teoría política, Paidós, Barcelona, 1999, p. 170.

${ }^{19}$ Habermas, J., Facticidad y validez, Trotta, Madrid, 2005, p. 193.

${ }^{20}$ Habermas, J., Facticidad y validez, Trotta, Madrid, 2005, p. 194. En la medida en que los derechos humanos garantizan las condiciones para desarrollar un proceso político comunicativo, ellos "no son tanto condiciones restrictivas como habilitadoras del ejercicio de la soberanía popular". Habermas, J., "Derechos humanos y soberanía popular: Las concepciones liberal y republicanas”, Derechos y libertades. Revista del Instituto Bartolomé de las Casas, No 3, 1994, pp. 229-230.

${ }^{21}$ Es así que "los ciudadanos solo pueden hacer uso apropiado de su autonomía pública si son suficientemente independientes en virtud de una autonomía privada asegurada de manera homogénea; pero que a la vez solo pueden lograr una regulación susceptible de consenso de autonomía privada si en cuanto ciudadanos pueden hacer uso apropiado de su autonomía política". Habermas, J., "Derechos humanos y soberanía popular: Las concepciones liberal y republicanas", Derechos y libertades. Revista del Instituto Bartolomé de las Casas, No 3, 1994, p. 255.

${ }^{22}$ Anderson, P., Spectrum. De la derecha a la izquierda en el mundo de las ideas, Akal, Madrid, 2008, p. 135. 
Habermas se pregunta por los derechos que se otorgarían mutuamente los ciudadanos y responde en términos de una autolegislación que supone que todos los destinatarios del derecho puedan entenderse como sus autores. En definitiva, aquello que supone no es otra cosa que el consenso entre los ciudadanos, algo que se advierte con claridad en el tratamiento que hace de la obra de Jean-Jacques Rousseau.

De acuerdo con Habermas, han sido Rousseau y Kant quienes más se han aproximado al objetivo de exponer la mutua implicación que existe entre los derechos humanos y la soberanía popular, pero mientras el ginebrino quedó atrapado en una lectura demasiado republicana de la autonomía política, el autor nacido en Königsberg mantuvo una mirada excesivamente liberal ${ }^{23}$. En el caso de Rousseau, "el ejercicio de la autonomía política no puede permanecer condicionado por la existencia de derechos innatos" 24 , por lo que el contenido normativo de los derechos humanos "se concentrará más bien en el propio modo de realización de la soberanía popular" ${ }^{25}$. Más allá del extraño lenguaje con el que alude a Rousseau -en cuyas obras cuesta encontrar referencias a los derechos del hombre-, aquí me interesa remarcar la crítica que realiza Habermas. El problema que plantea la propuesta de Rousseau se vincula con las dificultades que se suscitan entre la obligatoria orientación ética de los ciudadanos y sus intereses particulares. La cuestión conflictiva no se encuentra en el proceso de constitución colectiva de la voluntad general, sino en la coerción utilizada contra aquellos que no quieran someterse a ella. Para Habermas, Rousseau no logra explicitar cómo se podría establecer una mediación entre la orientación de los ciudadanos hacia el bien común y los diferentes intereses privados: no logra exponer "cómo sin represión cabría establecer una mediación entre la voluntad general construida normativamente y el arbitrio de los individuos" ${ }^{26}$. En definitiva, Rousseau "[n]o puede explicar cómo esa voluntad común normativamente construida puede, sin coerción, ser alcanzada, mediante la libre elección de los individuos" 27 .

Si bien esta crítica a Rousseau puede parecer insignificante en comparación con toda la labor reconstructiva habermasiana, creo que muestra el gesto que introduce para pensar lo político y dota de inteligibilidad a los resultados obtenidos por esa labor. Habermas puede desplegar un acto de pacificación, de anular toda necesidad de coacción, sí y solo sí supone el consenso entre todos los individuos. En la obra de Rousseau el ejercicio de la coacción soluciona el problema de la falta de consenso, la dificultad suscitada cuando los destinatarios no lograban verse a sí mismos como autores de las normas. En la obra del autor alemán no es necesario apelar a la coacción porque se supone el consenso. No

${ }^{23}$ Habermas, J., Facticidad y validez, Trotta, Madrid, 2005, pp. 160-169. Habermas, J., "Derechos humanos y soberanía popular: Las concepciones liberal y republicanas", en Derechos y libertades. Revista del Instituto Bartolomé de las Casas, $\mathrm{N}^{\circ}$ 3, 1994, p. 222.

${ }^{24}$ Habermas, J., "Derechos humanos y soberanía popular: Las concepciones liberal y republicanas", en Derechos y libertades. Revista del Instituto Bartolomé de las Casas, N³, 1994, p. 227.

${ }^{25}$ Habermas, J., "Derechos humanos y soberanía popular: Las concepciones liberal y republicanas", en Derechos y libertades. Revista del Instituto Bartolomé de las Casas, No 3, 1994, p. 227.

${ }^{26}$ Habermas, J., Facticidad y validez, Trotta, Madrid, 2005, p. 167.

${ }^{27}$ Habermas, J., "Derechos humanos y soberanía popular: Las concepciones liberal y republicanas", en Derechos y libertades. Revista del Instituto Bartolomé de las Casas, No 3, 1994, p. 228. 
existe la posibilidad que no se alcance. En el trabajo de Rousseau tampoco sería necesaria la coacción si se lograra el consenso, si no se produjera una tensión entre la voluntad general y voluntades particulares, pero como cree que uno de los posibles resultados de la deliberación es el disenso, su drama es cómo responder a quienes no se ajustan a la voluntad general ${ }^{28}$. En los trabajos de Habermas este drama no existe porque el disenso no es uno de los resultados posibles de la deliberación. Su gesto no es otro que cambiar, casi como un ilusionista juega con las barajas, el disenso (y la coacción) por el consenso. Es así que bajo las condiciones pragmáticas del discurso "la pretensión de que una norma descanse igualmente en el interés de todos significa que es aceptable racionalmente -todos los posibles afectados por ella deberían poder contar con buenas razones para aceptarla"29.

Bajo la premisa de desechar la coerción porque se supone el consenso, Habermas entiende que las miradas de Rousseau y Kant "carecen de la fuerza legitimatoria de un proceso discursivo de formación de opinión y voluntad, en el que las fuerzas expresivas y vinculantes que todos, en tanto que individuos, podrían aceptar libremente, sin ningún tipo de coerción”30. Aquí no solamente Habermas presenta las exigentes condiciones que han de cumplirse si se aplica el principio del discurso, sino que además supone que una vez cumplidas se garantiza el consenso sobre el mejor argumento. Sin embargo, aun cumplidas estas exigencias "no hay ninguna razón particular para pensar que la deliberación acercará a las personas, incluso aunque ellas lo deseen” 31 . Esto es así porque la deliberación "puede revelar tanto diferencias ocultas como posibilidades ocultas para la convergencia"32.

El proyecto habermasiano que busca dar cuenta de la conexión interna entre la autonomía privada y la autonomía pública se basa en una concepción de la autolegislación entendida en términos discursivos, en la que los destinatarios de las normas deberían ser sus autores. Este proceso supone que todos los autores/destinatarios, luego de un proceso de deliberación acuerden entre sí. Según creo no hay mayores razones para tener por ilegítimas normas o sistemas de derechos consentidos por todos: si individuos libres e iguales dialogan en un contexto en el que no se entrometen las relaciones de poder, y acuerdan los derechos que mutuamente desean consagrarse, intuyo que nadie podría

${ }^{28}$ Rousseau indica que con la excepción del contrato primitivo -que requiere unanimidad- las decisiones colectivas mayoritarias que constituyan una voluntad general obligan a los demás. Quienes han expresado una voluntad distinta estaban en un error y por eso someterlos a la voluntad general no es otra cosa que obligarlos a ser libres. Rousseau, J. J., Du contrat social ou principes du droit politique, Librairie des bibliophiles, Paris, 1889, IV, 2, pp. 132-34.

${ }^{29}$ Habermas, J., "Derechos humanos y soberanía popular: Las concepciones liberal y republicanas", en Derechos y libertades. Revista del Instituto Bartolomé de las Casas, No 3, 1994, p. 228.

${ }^{30}$ Habermas, J., "Derechos humanos y soberanía popular: Las concepciones liberal y republicanas", en Derechos y libertades. Revista del Instituto Bartolomé de las Casas, No 3, 1994, p. 228.

${ }^{31}$ Shapiro, I., "Enough of deliberation: Politics is about interests and power", en Macedo, S., Deliberative politics. Essays on democracy and disagreement, Oxford University Press, New York, 1999, p. 31.

${ }^{32}$ Shapiro, I., "Enough of deliberation: Politics is about interests and power", en Macedo, S., Deliberative politics. Essays on democracy and disagreement, Oxford University Press, New York, 1999, p. 32. 
pensar que estamos frente a normas ilegítimas. Sin embargo, el problema está en suponer la existencia de algo tan complejo y tan difícil de lograr en la práctica política: la igualdad entre los ciudadanos y el consenso entre ellos. Suponiendo estos elementos resulta extremadamente fácil dotar de legitimidad al sistema de los derechos. Sin embargo, Habermas no solamente supone el consenso para formalizar y legitimar el sistema de los derechos, este no estaría presente únicamente en los "momentos constitucionales"33, sino que también asume su existencia en la práctica política cotidiana.

\section{La legitimidad de la dominación política}

La legitimidad del sistema de los derechos no debe confundirse con la legitimidad del ejercicio de la dominación política, pero la eficacia del sistema de los derechos depende de su institucionalización en un Estado de derecho ${ }^{34}$. Siguiendo los pasos de Habermas puede afirmarse que: a) el establecimiento del sistema de los derechos presupone la instauración de un poder de sanción por parte del Estado, b) el Estado de derecho reclama que las decisiones del poder estatal se legitimen ateniéndose al derecho legítimamente establecido y, c) en un contexto posmetafísico de justificación "solo puede tenerse por legítimo el derecho que pudiese ser racionalmente aceptado por todos los miembros de la comunidad jurídica en una formación discursiva de la opinión y la voluntad comunes". ${ }^{35}$ Para Habermas el poder político sitúa su autoridad normativa en su fusión con el derecho, y este solo puede constituirse legítimamente si logra movilizar las libertades comunicativas de los ciudadanos. Sin embargo, antes de continuar, hay que separar las nociones de poder político y poder administrativo-que por momentos parecen ser tratados indistintamente- del poder comunicativo. La cuestión central es entender que la administración estatal no puede legitimarse a sí misma, sino que debe contar con "un poder comunicativo productor de derecho" 36.

El poder comunicativo, que se construye en ámbitos deliberativos de la sociedad civil y está atravesado por la formación racional de opiniones comunes, genera una fuerza motivadora, constituye un poder comunicativo que termina influyendo sobre el poder

${ }^{33}$ Cfr. Ackerman, B. We the People. Foundations, Harvard University Press, Cambridge/Londres, 1991. Ackerman, B. We the People. Transformations. Harvard University Press, Cambridge/Londres, 1998.

${ }^{34}$ Para Habermas los "derechos subjetivos solo pueden ser puestos en vigor y solo pueden ser hechos cumplir por organizaciones que tomen decisiones colectivamente vinculantes. Y a su vez, estas decisiones deben su carácter colectivamente vinculante a la forma jurídica de que están revestidas. Esta interna conexión del derecho con el poder político se refleja en las implicaciones que en punto al derecho objetivo, tienen los derechos subjetivos". Habermas, J., Facticidad y validez, Trotta, Madrid, 2005, p. 200.

${ }^{35}$ Habermas, J., Facticidad y validez, Trotta, Madrid, 2005, p. 202.

${ }^{36}$ Habermas, J., Facticidad y validez, Trotta, Madrid, 2005, p. 214 . El sistema político "es un subsistema especializado en la toma de decisiones colectivamente vinculantes, mientras que las estructuras comunicativas del espacio público conforman una red ampliamente expandida de sensores que reaccionan ante la presión de los problemas que afectan a la sociedad en su conjunto y que además estimulan la generación de opiniones de mucha influencia. La opinión pública transformada en poder comunicativo mediante procedimientos democráticos no puede «mandar» ella misma, sino solo dirigir el uso del poder administrativo hacia 
administrativo. Incluso cuando esta fuerza motivadora "no tenga otro alcance que el de la fuerza motivadora débil que caracteriza a las buenas razones" 37 es generadora de "potenciales de poder" 38 . Habermas supone que "al movilizarse las libertades comunicativas de los ciudadanos para la generación de derecho legítimo, tales obligaciones ilocucionarias se adensan formando un potencial con el que han de contar quienes ocupan posiciones de poder administrativo"39. Aquí es interesante marcar cierto desplazamiento conceptual, porque mientras en trabajos anteriores apelaba a la metáfora del equilibrio para referirse a la relación de debería existir entre el sistema económico, el sistema político-administrativo y el mundo de la vida, en Facticidad y validez la metáfora es eliminada y el poder comunicativo parece ser el fundamento de legitimidad del poder político-administrativo ${ }^{40}$. Pero además es importante subrayar otro aspecto: si en numerosas oportunidades expuso el desarrollo de un procedimiento deliberativo exento de relaciones de poder, ahora brinda a los acuerdos comunicativos un poder. Un poder tan robusto que logra incidir en las decisiones del poder administrativo. Creo que apelar a la existencia de prácticas comunicativas que son ajenas a relaciones de poder, pero que logran generar poder resulta, cuanto menos, extraño.

Esta íntima conexión entre poder administrativo y poder comunicativo es un requisito fundamental del Estado de derecho, que puede conceptualizarse como "la exigencia de ligar el poder administrativo, regido por el código «poder», al poder comunicativo creador de derecho, y mantenerlo libre de interferencias del poder social, es decir, de la fáctica capacidad de imponerse que tienen los intereses privilegiados" ${ }^{41}$. Teniendo esto en cuenta puede afirmarse que "el poder administrativo no tiene que reproducirse a sí mismo sino solo regenerarse a partir de la metamorfosis de poder comunicativo" 42 . Este desarrollo es interesante no solamente porque Habermas caracteriza al Estado de derecho, sino porque reconoce la existencia de intereses que tienen la capacidad fáctica de condicionar el poder administrativo. También es un pasaje importante porque enfatiza que es estrictamente necesario mantener libre al poder político de tales injerencias. El problema es que en ningún momento indica cómo esto es posible, a menos que esté sugiriendo que el fantasmático poder comunicativo, por sí mismo, posibilita aislar los peligros de interferencia que pueden tener estos intereses. Así como suponía

determinados canales". Habermas, J., "Tres modelos normativos de democracia", en La inclusión del otro. Estudios de teoría política, Paidós, Barcelona 1999, pp. 244.

Como bien resume Benhabib "en las sociedades democráticas complejas la legitimidad debe ser pensada como el resultado de la libre e irrestricta deliberación pública de todos sobre asuntos de interés común. De este modo, una esfera pública de deliberación sobre materias de interés común es esencial para la legitimidad de las instituciones democráticas”. Benhabib, S., "Toward a Deliberative Model of Democratic Legitimacy”, en Banhabib, S. (Ed.), Democracy and Difference, Princeton University Press, Princeton, 1996, p. 68.

${ }^{37}$ Habermas, J., Facticidad y validez, Trotta, Madrid, 2005, p. 214.

${ }^{38}$ Habermas, J., Facticidad y validez, Trotta, Madrid, 2005, p. 214.

${ }^{39}$ Habermas, J., Facticidad y validez, Trotta, Madrid, 2005, pp. 214-215.

${ }^{40}$ Anderson, P., Spectrum. De la derecha a la izquierda en el mundo de las ideas, Akal, Madrid, 2008, p. 138.

${ }^{41}$ Habermas, J., Facticidad y validez, Trotta, Madrid, 2005, p. 218.

${ }^{42}$ Habermas, J., Facticidad y validez, Trotta, Madrid, 2005, p. 218. 
cierto consenso al momento de formalizar el sistema de los derechos, y luego mantiene ese supuesto para construir el poder comunicativo, ahora parece suponer que el poder político se puede mantener aislado de los poderes privilegiados.

La formación de la voluntad y opinión común que supone el poder comunicativo debe hacer valer el principio del discurso en dos sentidos: a) en un sentido cognitivo, que supone la capacidad de filtrar los argumentos y las informaciones de modo tal que "los resultados alcanzados tengan a su favor la presunción de aceptabilidad racional" 43 ; b) en un sentido práctico, que refiere a la posibilidad de "establecer relaciones de entendimiento que vengan «exentas de violencia» [...] desencadenen la fuerza productiva que la libertad comunicativa representa" ${ }^{44}$. Es notable cómo Habermas desplaza de la política la gramática de la violencia, el poder, y el conflicto de intereses, y la inscribe en el intercambio comunicativo, y luego insiste que "[e]l principio del discurso, y esta es su nota más general, hace depender la validez de toda clase de normas de acción del asentimiento de aquellos que como afectados participan en «discursos racionales»" 45 . Si antes suponía que los intereses privilegiados no se filtraban en el poder político -o había manera de detenerlos-, ahora reinicia el derrotero para suponer el consenso, ya que el principio del discurso hace depender la validez de las normas del consentimiento de los afectados. Sin embargo a la lista de elementos que Habermas supone hay que agregar uno más: los ciudadanos desean cooperar para solucionar sus conflictos.

Cuando un colectivo de personas se enfrenta a la cuestión ¿Qué debemos hacer? se encuentra ante problemas que "han de ser resueltos en términos cooperativos" 46 , y cuando se plantean conflictos deben "resolverse en términos consensuales" ${ }^{47}$. En la deliberación sobre decisiones legislativas la pregunta por aquello que "debemos hacer" puede responderse teniendo en cuenta aspectos pragmáticos, éticos y morales, que no tienen la misma forma de argumentación, pero están montados en la supuesta búsqueda cooperativa de soluciones. En vistas de articular la producción del derecho y el poder comunicativo, Habermas propone partir de cuestiones pragmáticas, para luego hacer transitar los argumentos en los términos del discurso ético, y finalmente de compromisos morales ${ }^{48}$.

${ }^{43}$ Habermas, J., Facticidad y validez, Trotta, Madrid, 2005, p. 218.

${ }^{44}$ Habermas, J., Facticidad y validez, Trotta, Madrid, 2005, p. 218. Al aludir a relaciones "exentas de violencia" Habermas retoma algunos desarrollos de Hannah Arendt. En Sobre la violencia, la autora alemana diferenció el concepto de poder del de violencia -caracterizado por la mera instrumentalidad-, y postuló que se trata de nociones antitéticas entre sí: "políticamente hablando, es insuficiente decir que poder y violencia no son lo mismo. El poder y la violencia son opuestos; donde uno domina absolutamente, el otro está ausente. La violencia aparece donde el poder está en peligro pero, confiada a su propio impulso, acaba por hacer desaparecer al poder. Esto implica que no es correcto pensar que lo opuesto de la violencia es la no violencia; hablar de un poder no violento constituye en la actualidad una redundancia”. Arendt, H. On Violence, Harcourt, Brace \& World, New York, p. 1969.

45 Habermas, J., Facticidad y validez, Trotta, Madrid, 2005, p. 226.

${ }^{46}$ Habermas, J., Facticidad y validez, Trotta, Madrid, 2005, p. 226.

${ }^{47}$ Habermas, J., Facticidad y validez, Trotta, Madrid, 2005, p. 226.

48 Así, "en la formación de la opinión y la voluntad discursivamente estructurada de un legislador político se entrelaza la producción del derecho con la formación de poder comunicativo. Esta conexión podemos aclarárnosla recurriendo a un modelo procesual articulado en términos de lógica de la argumentación, que 
La formulación de compromisos políticos no puede sustituir a los principios morales porque, justamente, la voluntad política no puede quedar reducida a la constitución de compromisos. Del mismo modo, los discursos ético-políticos deben ser compatibles con los principios morales. Es de suma importancia tener esto presente, pues la forma de la moralidad exige la universalización, y "el principio de universalización obliga a los participantes en el discurso a averiguar, recurriendo a casos particulares previsiblemente típicos, si las normas en cuestión podrían encontrar el asentimiento meditado de todos los afectados" ${ }^{49}$. Si asumimos las condiciones del pensamiento posmetafísico, los discursos ético-políticos nos conducen a "regulaciones que de por sí sean en igual interés de todos los miembros" 50 . Según entiendo, aquí hay dos elementos que son muy importantes. El primero se vincula con un aspecto que Habermas presenta como un desagregado analítico de sus desarrollos, pero que no lo es. No solamente vuelve a suponer regulaciones a partir de consensos, sino que además esa regulación cumple el "igual interés de todos sus miembros”. Podemos suponer la existencia de un consenso entre sectores antagónicos, por ejemplo entre el capital y el trabajo, pero de ello nunca puede derivarse que esos acuerdos "sean en igual interés de todos los miembros". A los individuos iguales, a la deliberación sin coacciones, al consenso, a este imaginario listado de supuestos, ahora debemos anotar la satisfacción igualitaria de los intereses de todos los miembros. El segundo elemento importante se vincula con la forma de los argumentos morales.

Para que se aplique con total rigor el principio del discurso, la deliberación política puede plantearse en términos pragmáticos o éticos, pero en algún momento debe elevarse a la forma de la moralidad, debe exigir la universalidad, y esto implica que todos los afectados estén dispuestos a consentir la decisión ${ }^{51}$. La dominación política es legítima solo si se sustenta en leyes que los ciudadanos se dan a sí mismos, pero no bajo cualquier tipo de proceso sino bajo uno atravesado por el principio del discurso,

parte de las cuestiones pragmáticas, que a través de la ramificación en formación de compromisos y discursos éticos progresa hacia la aclaración de cuestiones morales". Habermas, J., Facticidad y validez, Trotta, Madrid, 2005 , p. 230.

${ }^{49}$ Habermas, J., Facticidad y validez, Trotta, Madrid, 2005, p. 230.

${ }^{50}$ Habermas, J., Facticidad y validez, Trotta, Madrid, 2005, p. 235.

${ }^{51}$ En "Ética del discurso" sugería que más allá de las diferentes formulaciones del imperativo categórico kantiano el principio subyacente era el carácter general o impersonal de los mandatos morales, lo que implica descartar las normas morales que no serían aprobadas por los potenciales afectados. Detrás de la idea de universalización se encuentra la intuición según la cual "las normas válidas han de ganar el reconocimiento de todos los afectados". Habermas, J. "Ética del discurso. Notas sobre un programa de fundamentación”, en Conciencia moral y acción comunicativa, Península, Barcelona, 1985, p. 85. El postulado de la universalización implica que "únicamente pueden aspirar a la validez aquellas normas que consiguen (o puedan conseguir) la aprobación de todos los participantes en cuanto participantes de un discurso práctico”. Habermas, J. "Ética del discurso. Notas sobre un programa de fundamentación", en Conciencia moral y acción comunicativa, Península, Barcelona, 1985, 117. Ahora bien, como no podría ser de otro modo, estructura de la comunicación excluye toda coacción: "[1]os participantes de la discusión no pueden soslayar el presupuesto de que, en función de unos rasgos que se han de describir formalmente, la estructura de su comunicación excluye toda coacción que, no siendo un argumento mejor, influya sobre el proceso de compresión”. Habermas, J. "Ética del discurso. Notas sobre un programa de fundamentación", en Conciencia moral y acción comunicativa, Península, Barcelona, 1985, p. 112. 
que supone un tratamiento racional de las cuestiones políticas. De este modo, la "aceptabilidad racional de los resultados obtenidos [...] se explica por la institucionalización de una red de formas de comunicación que, en idea, aseguran que todas las cuestiones, temas y contribuciones relevantes puedan hacerse oír y se aborden y elaboren en discursos y negociaciones sobre la base de las mejores informaciones y razones posibles" 52 . Si reconstruimos la presentación de Habermas es posible resumir que: a) la respuesta a qué debemos hacer, hay que buscarla en términos cooperativos, excluyendo toda confrontación, conflicto y antagonismos; b) no solamente debemos encontrar una respuesta en términos cooperativos, sino que la regulación a la que lleguemos debe satisfacer el "igual interés de todos los miembros"; c) todo esto es posible en tanto y en cuanto las discusiones se realicen sobre "la base de las mejores informaciones y razones posibles". Sin embargo, para que todos estos supuestos se puedan dar por cumplidos, es menester asumir determinado funcionamiento de la sociedad civil, algo que Habermas también (re)construye.

La sociedad civil debe ser pensada en términos abstractos, con "una textura asociativa y una cultura política que queden suficientemente desconectadas de las estructuras de clase" 53 . La sociedad civil debe "amortiguar y neutralizar la desigual distribución de las posiciones de poder social y de los potenciales de poder que de ella resultan, de modo que el poder social solo se imponga en la medida en que facilite y no restrinja el ejercicio de la autonomía ciudadana" ${ }^{54}$. Creo que aquí hay cierto desplazamiento en los desarrollos de Habermas porque ya no se supone la igualdad y libertad de los ciudadanos sino que, con mayor cercanía a la realidad, menciona la existencia de una desigual distribución de poder social. Habermas utiliza la expresión " «poder social» como medida de la posibilidad que un actor tiene de imponer en las relaciones sociales sus propios intereses aun en contra de la resistencia de los otros" 55 . Creo que podría encontrarse un excesivo liberalismo -o una gran ingenuidad-al momento de concebir el poder social no en relación a clases o grupos de interés, sino en relación a "actores" individuales. Sin embargo quisiera concentrarme en otra variable: aunque Habermas se hace cargo de la existencia de una desigual distribución de poder, asume que la sociedad civil puede neutralizarla y hacer valer la autonomía política. Sin embargo, como postula Anderson con algo de ironía, "con independencia de lo desigual que pueda ser el equilibrio de poder entre -pongamos, por usar términos que casi nunca se encuentran en Faktizität und Geltung-capital y trabajo, el resultado jurídico de un proceso de negociación entre ellos será «justo», siempre que se les de igual oportunidad de hablar entre sí. Con este movimiento de la varita mágica, la desigualdad se convierte después de todo en algo parecido a la igualdad" 56.

En una entrevista que le realizaron en 1994 le preguntaron si su caracterización de la sociedad civil tenía sustento empírico, ya que al contrario de sus reconstrucciones

\footnotetext{
52 Habermas, J., Facticidad y validez, Trotta, Madrid, 2005, p. 238.

53 Habermas, J., Facticidad y validez, Trotta, Madrid, 2005, p. 243.

${ }^{54}$ Habermas, J., Facticidad y validez, Trotta, Madrid, 2005, p. 243.

55 Habermas, J., Facticidad y validez, Trotta, Madrid, 2005, p. 243.

56 Anderson, P., Spectrum. De la derecha a la izquierda en el mundo de las ideas, Akal, Madrid, 2008, p. 137.
} 
suele estar dominada por los medios de comunicación concentrados, y atravesada por desigualdades de clase y sexo. También se le consultó sobre el modo de distinguir entre impulsos democráticos y antidemocráticos de la sociedad civil. Sin embargo evadió responder esos interrogantes y se limitó a decir que "[e]l poder comunicativo solo se forma en espacios públicos que establecen relaciones comunicativas sobre la base de un reconocimiento recíproco y que posibilitan el uso de las libertades comunicativas" 57 . Por su lado, en "Tres modelos normativos de democracia" incluye otra extraña caracterización de la sociedad civil, porque la presenta como distante del poder administrativo y de los poderes económicos, "alejada por igual del Estado como de la Economía" 58 . Lo notable es que para lograr que la sociedad civil se desempeñe con estas características, Habermas reconoce la necesidad de mantener domesticados a los medios de comunicación y al capitalismo ${ }^{59}$. Sin embargo no solamente no indica cómo es posible domesticarlos, sino que en la medida en que el paradigma del derecho que defiende Habermas es meramente formal, no resulta muy claro que la mera formalidad nos dirija, necesariamente, hacia esa necesitada domesticación ${ }^{60}$. De todos modos Habermas asume que así será.

A la suma de supuestos ya reseñados hay que añadir cierto funcionamiento de la sociedad civil: tiene una textura asociativa y una cultura política desconectada de las diferencias de clases, presenta asociaciones libres, es capaz de neutralizar la desigual distribución de poder social y mantener dominados al capitalismo y a los medios de comunicación. Sin embargo resulta todavía más extraño lo que enuncia a propósito del poder social: Habermas entiende que puede posibilitar la formación del poder comunicativo, pero también puede restringirlo. Esto último se produce cuando el "poder social abre la posibilidad de ejercer una influencia sobre el proceso político, que, allende el ámbito de los derechos ciudadanos de igualdad, da primacía a los propios intereses de uno" ${ }^{61}$. La transformación de poder social en poder político puede desarrollarse a partir de una influencia directa en el poder administrativo o mediante la manipulación de la opinión pública. El inofensivo remedio que propone para evitar que el poder social se transforme en poder político es la responsabilidad democrática de los legisladores, la periodicidad de sus mandatos: "el principio de que ha de bloquearse toda intervención directa del poder social en poder administrativo, encuentra expresión en el principio de la responsabilidad democrática de quienes ocupan cargos públicos frente a sus electores y frente a sus parlamentos. Los diputados han de exponerse periódicamente a nuevas elecciones" ${ }^{2}$. Son las elecciones la única estrategia que brinda para evitar que el poder

57 Habermas, J., “ «Facticidad y validez». Una conversación sobre teoría política”, en Más allá del Estado nacional, Fondo de Cultura Económica, México DF, 1999, pp. 160-161.

${ }^{58}$ Habermas, J., "Tres modelos normativos de democracia”, en La inclusión del otro. Estudios de teoría política, Paidós, Barcelona 1999, pp. 245.

${ }^{59}$ Habermas, J., Facticidad y validez, Trotta, Madrid, 2005, p. 492.

60 Anderson, P., Spectrum. De la derecha a la izquierda en el mundo de las ideas, Akal, Madrid, 2008, pp. 140-141.

${ }^{61}$ Habermas, J., Facticidad y validez, Trotta, Madrid, 2005, pp. 243-244.

${ }^{62}$ Habermas, J., Facticidad y validez, Trotta, Madrid, 2005, p. 244. 
social se transforme en poder administrativo, pero en su labor reconstructiva no explica cómo la responsabilidad de los representantes permite contener al poder social. Una vez más, asume que es y será así.

Luego de este extenso recorrido conceptual, y tras de plantear que el único criterio de legitimidad del sistema de los derechos y del poder político radica en procedimientos deliberativos que se desarrollan entre individuos libres e iguales que conducen a un acuerdo entre los participantes y potenciales afectados, Habermas reconoce que "[a] causa de su contenido idealizador los presupuestos comunicativos universales de las argumentaciones solo pueden cumplirse aproximativamente" 63 . Sin embargo, no solamente admite que los presupuestos comunicativos son ideales sino que además, luego de insistir en innumerables oportunidades en que las leyes deben ser aceptadas por todos los afectados, que el principio del discurso exige que la argumentación debe tomar la forma moral $-\mathrm{y}$ por ello los resultados deben ser consentidos universalmente-, termina aceptando la regla de la mayoría al momento de adoptar las decisiones ${ }^{64}$. Incluye la regla de la mayoría para mostrar que la institucionalización jurídica constituiría, en términos de Rawls, una racionalidad o justicia procesal imperfecta y por ello las decisiones mayoritarias podrían rediscutirse ${ }^{65}$. Esto no merece mayores objeciones pero lo realmente problemático es que de un soplido, admitiendo la regla de la mayoría, destruye las bases de un edificio sustentado en el consenso de todos los implicados. ¿Dónde queda la legitimidad del sistema de los derechos y del poder político edificada bajo el manto sacrosanto del consenso cuando se admite la regla de mayoría? Habermas construye su propuesta teórica montada sobre varios supuestos que muy difícilmente se correspondan con las prácticas políticas modernas: igualdad entre los ciudadanos, no interferencia del poder social, consenso en las decisiones. Sin embargo cuando su reconstrucción se aproxima a las prácticas políticas modernas, basadas en la regla de la mayoría, borra de un plumazo todos sus supuestos, y con ello los fundamentos del sistema de los derechos y el poder político.

\section{Democracia Deliberativa y DEMOCRACIA AGONÍSTICA}

Algunas similitudes con los desarrollos que aquí he planteado pueden leerse en los trabajos de Chantal Mouffe, quien a la noción de democracia deliberativa ha opuesto

${ }^{63}$ Habermas, J., Facticidad y validez, Trotta, Madrid, 2005, p. 247.

${ }^{64}$ Para Habermas "[1]a regla de la mayoría [...] constituye un buen ejemplo de un importante aspecto de la regulación de los procesos de deliberación en términos de derecho procedimental”. Habermas, J., Facticidad y validez, Trotta, Madrid, 2005, p. 247.

${ }^{65}$ Sobre la conceptualización de justicia procesal imperfecta ver Rawls, J., A Theory of Justice, Harvard University Press, Cambridge, 2005, pp. 75-76. Sobre el modo en que piensa la justicia política y el proceso político como un caso de justicia procesal imperfecta, ver Rawls, J., A Theory of Justice, Harvard University Press, Cambridge, 2005, pp. 194-200. 
la de "democracia agonística" o "pluralismo agonístico". Sin embargo creo que mis objeciones son sensiblemente diferentes, en un sentido más leve y en otro más potente.

En El retorno de lo político, publicado al año siguiente que Facticidad y validez, Mouffe entiende que a partir de la crisis del marxismo varios teóricos postularon que para pensar lo político era posible prescindir del antagonismo. Autores como Rawls y Habermas desplazaron el antagonismo político por consensos basados en acuerdos racionales inclusivos $^{66}$. Sin embargo, uno de los problemas que plantean estos enfoques radica en la imposibilidad de prescindir del antagonismo, que es constitutivo de lo político ${ }^{67}$. El antagonismo es el que permite la formación de las identidades políticas, que son siempre colectivas, y que implican una demarcación y una constitución de un "ellos" y un "nosotros". Es por ello que "la condición misma de posibilidad de formación de las identidades políticas es al mismo tiempo la condición de imposibilidad de una sociedad de la cual pudiera eliminarse el antagonismo" 68 .

Para Mouffe las democracias modernas deben transformar el antagonismo en agonismo, deben tener por objetivo convertir la relación entre enemigos en una relación entre adversarios ${ }^{69}$. Desde la perspectiva del pluralismo agonístico, que el enemigo sea tenido como un adversario implica que sea concebido como "alguien cuyas ideas combatimos pero cuyo derecho a defender esas ideas no ponemos en duda" ${ }^{70}$. Esta interacción entre adversarios no debe entenderse como algo corrosivo de la democracia sino como un elemento constitutivo: "la democracia no puede sobrevivir sin ciertas formas de consenso [...] pero también debe permitir que el conflicto se exprese, y eso requiere la constitución de identidades colectivas en torno a posiciones bien diferenciadas" 71 . Los desarrollos de Habermas niegan el rol central que tiene el conflicto tanto en la constitución de la política cuanto en la formación de las identidades colectivas $^{72}$, en parte porque ignora el papel de las pasiones, "es decir, aquella dimensión afectiva que ocupa un lugar central en la constitución de las formas colectivas de identificación"73.

Por otra parte, no tiene demasiado sentido postular la existencia de acuerdos sobre los principios de justicia, ya que si bien es probable lograr un consenso sobre los derechos del hombre, la libertad y la igualdad, la confrontación se suscita al momento de

${ }^{66}$ Mouffe, C., "Introducción. Por un pluralismo agonístico", en El retorno de lo político, Paidós, Barcelona, 1999 , pp. 11-12.

${ }^{67}$ Mouffe, C., "Democracia y pluralismo agonístico", en Derecho y bumanidades N $^{\circ} 12,2006$, p. 18.

${ }^{68}$ Mouffe, C., "Democracia y pluralismo agonístico", en Derecho y bumanidades, No 12, 2006, p. 21.

${ }^{69}$ Mouffe, C., "Democracia y pluralismo agonístico", en Derecho y bumanidades, N 12, 2006, p. 21.

${ }^{70}$ Mouffe, C. "For an Agonistic Model of Democracy", en The democratic paradox, Verso, London, 2000 , p. 102.

${ }^{71}$ Mouffe, C., "Introducción. Por un pluralismo agonístico", en El retorno de lo político, Paidós, Barcelona, 1999, pp. 16-17.

${ }^{72}$ Mouffe, C., "Deliberative Democracy or Agonistic Pluralism?", en Social Research, vol. 66, N 3 , 1999 , p. 752.

${ }^{73}$ Mouffe, C., "Feminismo, democracia y política agonística", en Debate feminista, $\mathrm{N}^{\circ} 40$, año 20, 2009, pp. 88-89. 
interpretar esos principios ${ }^{74}$. Incluso suponiendo un acuerdo en el sistema de los derechos existe un momento de confrontación: con el adversario se comparten los principios pero se disiente en el modo de aplicarlos ${ }^{75}$. El propósito de la política democrática nunca puede ser erradicar el poder sino que debe ampliar los ámbitos en los cuales las relaciones de poder puedan ser tamizados por un funcionamiento democrático. Imaginar algo así como una condición ideal de habla no implica otra cosa que "eliminar el lugar del adversario y excluir la cuestión propiamente política, la del antagonismo y el poder"76. Además, en la medida en que las relaciones de poder son constitutivas de nuestras formas de vida, es imposible concebir una deliberación no permeada por las prácticas de poder: "la libre e irrestricta deliberación pública de todos sobre asuntos de interés común es una imposibilidad conceptual, ya que las formas de vida particulares que se presentan como sus «impedimentos» son en gran medida su condición de posibilidad" 77 .

${ }^{74}$ En términos más próximos a la obra de Jacques Rancière, podría sostenerse que el momento del desacuerdo no se sitúa en la deliberación previa al acuerdo sobre los principios rectores de la política, sino el de su interpretación. El desacuerdo alude a "un tipo determinado de situación de habla: aquella en la que cada uno de los interlocutores entiende y a la vez no entiende lo que dice el otro. El desacuerdo no es el conflicto entre quien dice blanco y quien dice negro. Es el existente entre quien dice blanco y quien dice blanco pero no entiende la misma cosa o no entiende que el otro dice lo mismo bajo el nombre de blancura". Rancière, J., La mésentente. Politique et philosophie, Galilée, Paris, 1995, p. 12.

${ }^{75}$ Mouffe, C., "Democracia y pluralismo agonístico", en Derecho y bumanidades, No 12, 2006, p. 22. Es así que "[a]l modelo de inspiración kantiana de la democracia moderna hay que oponer otro, que no tiende a la armonía y la reconciliación, sino que reconoce el papel constitutivo de la división y el conflicto”. Mouffe, C., "Introducción. Por un pluralismo agonístico", en El retorno de lo político, Paidós, Barcelona, 1999, p. 24.

76 Mouffe, C., "Introducción. Por un pluralismo agonístico", en El retorno de lo político, Paidós, Barcelona, 1999, p. 24.

77 Mouffe, C. "For an Agonistic Model of Democracy", en The democratic paradox, Verso, London, 2000, p. 98. En otro orden de ideas, Mouffe también critica la posibilidad de concebir el diálogo racional en términos de neutralidad. Valiéndose de algunos de los desarrollos de Wittgenstein, postula que para lograr consensos primero debemos acordar en el uso del lenguaje, y ello implica un consenso en las formas de vida. Esto no es una cuestión menor porque si los consensos se logran por una forma de vida en común y no por un acuerdo de razones, el problema que contiene la propuesta de Habermas es que lo que se requiere es la reintroducción "dentro del proceso de deliberación de toda dimensión retórica que es precisamente lo que la perspectiva habermasiana del discurso se esfuerza por eliminar". Mouffe, C., "Deliberative Democracy or Agonistic Pluralism?”, en Social Research, vol. 66, No 3, 1999, p. 749. Además, la identificación con valores democráticos no depende únicamente del intercambio de razones, sino de un desarrollo de prácticas, valores y juegos de lenguaje. Esto permite, simultáneamente, rechazar la propuesta de la democracia deliberativa y avanzar hacia un modelo de democracia agonística.

En segundo lugar, la autora belga siembra sus dudas sobre la posibilidad de concebir a las "condiciones ideales de habla" como un espacio de comunicación intersubjetiva libre de coacciones en donde los participantes lleguen a un consenso por vía del mejor argumento. Además, tomando el modo en que Žižek se apropia de la obra de Lacan, puede decirse que el discurso posee una estructura autoritaria, porque de la libre dispersión de los significantes solo puede emerger un campo de significados si interviene un "significante amo". Es por ello que "Lacan socava la base misma del punto de vista habermasiano, según el cual los inherentes presupuestos pragmáticos del discurso son no autoritarios, ya que implican la idea de una comunicación libre de coacción donde solo cuenta la argumentación racional". Mouffe, C., "Deliberative Democracy or Agonistic Pluralism?”, en Social Research, vol. 66, No 3, 1999, p. 749. 
Si bien los desarrollos de Mouffe son más extensos, creo que su crítica central a las teorías deliberativas de la democracia radica en que ellas niegan el conflicto, y es la postulación del conflicto como constitutivo de lo político lo que permite construir la propuesta de una democracia sustentada en el pluralismo agonístico. Sin embargo me parece que la acusación de Mouffe no es completamente acertada porque Habermas no niega el conflicto, la disputa, y la confrontación. El problema es que supone que partiendo de ese conflicto se puede avanzar hacia un debate racional e igualitario que culmina en un consenso aceptado por todos y cada uno. Las dificultades de la propuesta habermasiana son menos graves que los subrayados por Mouffe porque Habermas no es tan ingenuo y no niega la existencia de la confrontación. Sin embargo, en otro sentido, su problema es más grave porque partiendo de la existencia del conflicto supone que puede solucionarse mediante un acuerdo racional.

Aquí es importante recordar que Habermas no propone una simple teoría normativa, sino que sus postulados normativos se derivan de una teoría reconstructiva que llega a los siguientes resultados: a) ciudadanos libres e iguales dispuestos a cooperar en los asuntos políticos; b) inexistencia de relaciones de poder en las deliberaciones políticas; c) sociedad civil conformada por ámbitos informales de deliberación; d) ausencia de intereses privilegiados, o confianza en que el principio del discurso logra que no se impongan en las discusiones y en los resultados; e) funcionamiento domesticado del capitalismo y de los medios de comunicación; f) consenso como resultado necesario de la deliberación; g) consenso que implica una igual satisfacción de los intereses de cada uno de los ciudadanos. Reiterar que no estamos frente a una simple propuesta normativa que enuncia cómo debería ser el camino para dotar de legitimidad al derecho y al poder político moderno, sino que estamos ante una labor reconstructiva que pretende dar cuenta de sus fundamentos implícitos, permite ubicar de modo adecuado el déficit de los desarrollos de Habermas. Su trabajo reconstructivo no niega el conflicto entre intereses antagónicos, pero tampoco tiene que explicar cómo el antagonismo puede transformarse en un consenso racional porque da por supuesto que así será. Su labor reconstructiva supone como resueltos los problemas más agobiantes para la teoría política: a) ante la pregunta por la legitimidad del derecho y del poder político en contextos de desigualdad, supone un escenario de igualdad; b) frente al interrogante por la legitimidad del derecho y del poder político en sociedades en las cuales ambos responden a los intereses de clase o de sectores privilegiados de la sociedad, supone que es posible dejarlos de lado y mantener una deliberación que se arrodille ante el mejor argumento; c) ante los dramas que genera el funcionamiento del sistema capitalista y el control que imponen los medios de comunicación, supone un capitalismo y un sistema mediático controlado; d) frente a la pregunta por la legitimidad del derecho y del poder en contextos donde el asentimiento de todos y cada uno los ciudadanos es imposible, reconstruye el consenso.

\section{Notas finales}

En la propuesta de Habermas es posible hallar elementos con los cuales resulta muy difícil estar en desacuerdo: el valor de la igualdad, la apuesta al diálogo como mecanismo para lograr acuerdos, el esfuerzo por pensar espacios públicos por fuera del 
Estado. Además, en términos generales, su desarrollo conceptual es coherente, sólido, y no presenta mayores contradicciones. Frente a la obra de Habermas lo que debemos preguntarnos es si para reflexionar sobre la legitimidad del derecho y del poder político nos interesa utilizar un andamiaje conceptual que suponga que los problemas más dramáticos y difíciles de resolver se encuentran solucionados. Lo que debemos analizar es si ante los interrogantes más dramáticos de la teoría del derecho y la teoría política, tiene sentido acudir a una propuesta teórica que no brinda respuesta a los interrogantes, sino que asume que ya están resueltos.

\section{BiBLIOGRAFÍA}

Ackerman, B., We the People. Foundations, Harvard University Press, Cambridge/Londres, 1991. We the People. Transformations. Harvard University Press, Cambridge/Londres, 1998.

Anderson, P., Spectrum. De la derecha a la izquierda en el mundo de las ideas, Akal, Madrid, 2008. Arendt, H., On Violence, Harcourt, Brace \& World, New York, p. 1969.

Benente, M., "El Foucault de Habermas bajo sospecha", en Nómadas. Revista crítica de ciencias sociales y jurídicas, $\mathrm{N}^{\circ} 35,2012$.

Benhabib, S., "Toward a Deliberative Model of Democratic Legitimacy", en Banhabib, S. (Ed.), Democracy and Difference, Princeton University Press, Princeton, 1996.

Borges, J.L., "Kafka y sus precursores", en Obras completas. 1923-1972, Emecé, Buenos Aires, 1974.

Elster, J., "Introduction”, en Elster, J. (ed.), Deliberative Democracy, Cambridge University Press, Cambridge, 1998.

Habermas, J., “Ética del discurso. Notas sobre un programa de fundamentación”, en Conciencia moral y acción comunicativa, Península, Barcelona, 1985.

, “Cómo es posible la legitimidad por vía de la legalidad?”, en Doxa, No 5, 1988.

, "Derechos humanos y soberanía popular: Las concepciones liberal y republicanas", en Derechos y libertades. Revista del Instituto Bartolomé de las Casas, N 3, 1994.

, "Tres modelos normativos de democracia", en La inclusión del otro. Estudios de teoría política, Paidós, Barcelona, 1999.

, "La lucha por el reconocimiento en el Estado democrático de derecho", en La inclusión del otro. Estudios de teoría política, Paidós, Barcelona, 1999.

, "El vínculo interno entre Estado de Derecho y Democracia", en La inclusión del otro. Estudios de teoría política, Paidós, Barcelona, 1999.

, “«Facticidad y validez». Una conversación sobre teoría política”, en Más allá del Estado nacional, Fondo de Cultura Económica, México DF, 1999.

"Derecho y moral", en Facticidad y validez, Trotta, Madrid: Trotta, 2005.

"La soberanía popular como procedimiento", en Facticidad y validez, Trotta, Madrid, 2005.

Facticidad y validez, Trotta, Madrid, 2005.

Mouffe, C., "Introducción. Por un pluralismo agonístico", en El retorno de lo político, Paidós, Barcelona, 1999.

, "Deliberative Democracy or Agonistic Pluralism?", en Social Research, vol. 66, N 3, 1999.

"For an Agonistic Model of Democracy", en The democratic paradox, Verso, London, 2000.

"Democracia y pluralismo agonístico", en Derecho y humanidades, No 12, 2006.

"Feminismo, democracia y política agonística", en Debate feminista, No 40, año 20, 2009.

Rancière, J., La mésentente. Politique et philosophie, Galilée, Paris, 1995. 
Rawls, J., A Theory of Justice, Harvard University Press, Cambridge, 2005

Rousseau, J.J., Du contrat social ou principes du droit politique, Librairie des bibliophiles, Paris, 1889. Shapiro, I., "Enough of deliberation: Politics is about interests and power", en Macedo, S.

(Ed.), Deliberative politics. Essays on democracy and disagreement. Oxford University Press, New York, 1999.

Weber, M., Economía y sociedad I, Fondo de Cultura Económica, México DF, 1944. 